\title{
Native Americans and Science: Enhancing Participation of Native Americans in the Science and Technology Workforce through Culturally Responsive Science Education
}

\author{
Gregory A. Cajete
}

\begin{abstract}
Aвstract A major issue that directly affects the participation of Native Americans in the science and technology workforce is the lack of preparation in science and math. This lack of preparation has many causes, but one of the most strategically important issues is the lack of culturally relevant curricula that engage Native American students in learning science in personal, social and culturally meaningful ways. This essay explores the needs, issues, research, and development of culturally responsive science education for Native American learners. A curriculum model created by the author at the Institute of American Indian Arts in Santa Fe, New Mexico, from 1974 to 1994 based on Native American cultural orientations is explored as a case study as one example of how to engage Native American students in science learning and become more prepared to participate in science and technology-related professions. As such, it presents a methodology for how trans-systemic work might be approached in building conceptual bridges between Indigenous and Western views of science.
\end{abstract}

KeYWords Native Americans, science education, culturally responsive education

\section{Lack of Native American Participation in Science Related Fields}

In January 1975, the American Association for the Advancement of Science Board (AAAS), led by Margaret Mead, passed a resolution that formally recognized the contributions made by Native Americans to the various fields of science, engineering, and medicine. They also supported natural and social science programs in which traditional Native American approaches and contributions to science, engineering and medicine were the subject of serious study and research.

Based on this mandate, Dr. Rayna Greene, director of the project on Native Americans in Science for the AAAS, advocated research and development of culturally responsive science. Through various studies, insights into the unique problems and perceptions of culturally responsive science programs have emerged. Dr. Greene summarized:

The lack of Indian participation in science is as much due to an alienation from the traditions of Western science as from a lack of access to science education, bad training in science, or any other reasons conventionally given for minority exclusion from scientific professionalism. Contrary to the general insistence of Western scientists that 
science is not culture bound and that it produces good, many native people feel that science and scientists are thoroughly Western, rather than universal, and that science is negative. (Greene, 1981. p. 8)

A difference in perception exists in a science directly related to the social and cultural nature of the society from which it originates. While the mandate of the AAAS and Dr. Green's (1981) comments were made over 40 years ago, the perceptions among many Native people that Western science is systemically biased in terms of access and practices continue to persist. This must be seriously addressed if Native Americans are to increase their active participation in the field of modern science (Medin \& Bang, 2014).

Keith James (2001), in his book Science and Native American Communities, summarizes the issues of science for Native communities. He states that there is recognition in Native community that there is a need for all forms of western education and skills. Still, there is also the recognition that western education, mainly related to science and technology as they are taught in schools, often does not align with the needs of the community or are inappropriate and ineffective in the social and cultural contexts of native communities. Native people educated in this form of education are often lured away from the reservation by corporations, governments, and urban centers, leading to what is referred to as the "reservation brain drain." There are economic roots, such as high unemployment levels, even for educated Indians: roots in the physical condition of the communities, such as poor infrastructure and equipment; sociological roots, such as family and community problems that weigh down many Indian students; and, institutional or programmatic roots, such as a history of materials and systems that are culturally inappropriate at best and assimilationist at worst (James, 2001, p. 2).

Other related issues are a long-standing mistrust of governmental and educational institutions, poor individual and community health, polarization and in-fighting between various groups, all of which make for deep struggle of both individuals and communities to emerge from such situations. Added to this is the impact of sometimes exploitive control of federal and corporate entities, which through various political and otherwise self-serving policies perpetuate weak social, governance, and economic structures, all of which add to lack of science participation and technology-related education.

In a statistical research study, Milne (2017) concludes the following:

Education, particularly the attainment of college degrees, is potentially one of the most powerful ways of transforming society. Education increases earning power through access to employment throughout life... Nation-wide in 2016,32\% of adults hold a baccalaureate (BA) degree or higher. Among 22 tribal communities in New Mexico in 2010 the average was $14 \%$ with 1,964 fewer degree-holders than expected for the population, equivalent to $\$ 488,090,000$ income per year. On that basis, $\$ 22,940,230$ of state tax revenue per year was missing that could have funded programs to increase degree completion. Relative to the US norm, the disparity is much higher. There is potential to fill a gap of over 56,000 degrees among New Mexico's 246,400 or more tribal people, which would net over $\$ 4.8$ billion earnings and increase per-capita 
wealth across the board. Optimism for disrupting the status quo comes from analysis of changes between 2000 and 2010 that reveal a 'structural trap' that limits most tribal communities to just $11 \%$ attainment of BAs. The trap could be eliminated by policies that amplify inter-generational, inter-tribal, and inter-institutional networks such as: (a) establishment of family and tribal community-owned college funds; (b) adoption of a life-long, inter-generational learning model throughout the New Mexico education system that enables students to re-enter as needed; (c) universal day-care tied to pre-school programs; and (d) work study programs for students to live and work within tribal communities while enrolled via distance-learning technology. Engagement with tribal communities and leaders in education and government will advance evidence-based solutions and narrow the gap in degree attainment. (Milne, 2017, p. 1)

Milne's research findings related to New Mexico Indian Tribes indicate the lack of degree attainment experienced by other Native Americans throughout the United States (2017). Similar economic and educational losses are characteristic of many Native communities (Medin \& Bang, 2014). The lack of attainment of science and technology degrees among Native Americans is even more acute, at the same time as the need for Native American people trained in science-related fields is increasing dramatically (James, 2001).

\section{Research Background}

The solution this essay presents advocates for an extension of the cumulative influences of tribal forms of traditional science, cultural-responsive education, and creative strategizing into the teaching and learning of science toward engaging, as opposed to alienating Native American students from science. The insights gained from research in these areas and their implications for how science is communicated to Native American students form the orienting basis for creating a culturally responsive science curriculum for Native American learners.

For Indians, education that is not grounded in tradition cannot succeed. Many studies have shown that incorporating Indian cultural principles and tribal languages into education increases students' success. Even if some individuals get through the standard mainstream education and achieve conventional success, communities still do not thrive. There are no Indians without Indian communities (Medin \& Bang, 2014).

Northwestern University researchers Medin and Bang (2014), contend that the very structuring of science education in most educational settings reflects an entrenchment of seeing science as being done in only one true way, with only one true set of values, seeing only one way to work in science, only one true curriculum for science. They believe such a biased orientation must be challenged and transformed toward a paradigm that acknowledges the relational nature of science and creates and supports science education for all.

After a detailed analysis of cultural differences between Native American and Euro-American approaches and practices in biological/ecological thinking and natural understanding the authors posit a solution (Medin \& Bang, 2014). They suggest that self-determination through community engagement with, and ownership of, Science and Science education may be the 
most crucial outcome for Native communities and Native people to become more engaged in science and technology-related fields.

Medin and Bang (2014) also contend that how science gets done reflects who's doing it. They believe that it is not as simple as everyone doing the same thing but not in the same way. They state that it is instead a matter of different things, done in different ways for different purposes guided by different [cultural and social] values. Contrary to prevailing assumptions, science is slow to self-correct, and entrenchment of the notion of "one truth, one way" continues to dominate. Medin and Bang (2014) argue for diversity and power-sharing within an educational framework designed to produce the best science and undermine research biases correlated to gender, race, socioeconomic status and culture. In other words, as is true in healthy ecological communities in nature, diversity strengthens the community and makes it more resilient. Alan Leshner (2011), CEO of the AAAS, writes:

Increasing the diversity of the scientific human resource pool will inevitably enhance the diversity of scientific ideas. By definition, innovation requires the ability to think in new and transformative ways. Many of the best new ideas, ideas that come from new participants in science and engineering enterprises, from those who have been less influenced by traditional scientific paradigms, thinking and theories...than those who have always been a part of the established scientific communities. (Leshner, 2011, p. 15)

Science is social and cultural, and an individual process of thought that has been utilized in some form by every human cultural group (Longino, 1990). The methods and products of science and their intimate relationships with human culture form an important part of education. Research in scientific knowledge transfer in an educational setting by scientists based on a cultural perspective is not extensive. Some of the research concerns the study of the relationship between scientific and artistic thinking in terms of characteristic brain functioning. The research in this area has come not from science educators or scientists but from individuals studying brain patterning characteristics, cultural learning, creativity, art, cognitive psychology, linguistics, holistic health, theoretical physics and cultural anthropology (Sanders, 1986; Hayward, 1984; Dunn, 1983; Capra, 1982; Gardner, 1982; Van Peursen, 1981; Mansfield, 1978; Hall, 1976).

For example, the scope of study in cultural anthropology encompasses all human activities - including science. Cultural anthropology is one of the few Western disciplines that seeks to understand a given aspect of a culture as a whole, both inside and on its own terms. This basic characteristic of the methodology of cultural anthropology lends itself most readily to the understanding of Western culture's realities through the "other's" eyes.

Individual attempts to investigate how cultural processes of classification and perception affect scientific thought were led by anthropologists like Benjamin Whorf and Magorah Maruyama in the 1960s and '70s. Maruyama and Harkins (1978) and others approached science as a cultural system. By examining conventional societal ideas, they began to widen the parameters of general scientific thought and knowledge. 
One of the significant insights into the cultural perception of "separate realities" came about due to the 1956 fieldwork of Benjamin Whorf among the Hopi Indians of Arizona. Whorf (1956) hypothesized that thought is intimately related to and even guided by a people's language. Implied is the idea that "realities" are different from one culture to the next. In an authentic sense, we are all wrapped up in our cultural blanket by our language, worldview and reality, and directly perceive and order the world in reference to this schema. Whorf proposed that Hopi terminology for certain aspects of physical reality reflected a better description of that reality than modern Western terminology. Western structuring of reality through language does not represent the exclusive legitimate perspective of reality.

Research indicates a "mismatch" between the perspective from which science is conventionally presented in American schools and the general cultural and individual learning orientations of Native Americans (Medin \& Bang, 2014). Hall (1975) adds:

Western science tends to overemphasize the process of classification at the expense of information about the organism... (which) has led Western thought to be predominately preoccupied with specifics to the exclusions of context of knowledge within wholes... ...How can integrative systems of thought be developed from a classification system that fragments and never gets around to putting things together in wholes. (p. 2)

One step further in the application of reductionism in education, is a lack of accepting that there are differences in individuals' learning orientations. Native American learners are a predominately visual group and context-oriented learners (Cajete, 1999). Science in most American schools is heavily oriented toward a learner who is presumed to be analytic, objective, verbal, structured, and parts oriented. Native American students tend to be intuitive, subjective, non-verbal, synthesizing and oriented to wholes (Cajete, 1999). For example, the study of the ethnoscience or cultural sciences and associated traditional ecological knowledge of the Indians of North America is a valuable tool for understanding the cultural influences in science and how Native and non-Natives gain valuable insights about themselves and the unconscious cultural conditioning of their perspectives of natural reality.

The Native or cultural science of each tribe or cultural region is unique and characteristic of that group or geological area in that it reflects adaptation to a certain place. However, "strands of connectedness" and similar patterns of cultural thought begin in the northern polar regions of North America and extend to the tip of South America. The mythical paradigms of the Trickster, the Sacred Twins, the Earth Mother, the Corn Mothers, the Thunderbirds, the Great Serpents, the Culture Hero, Grandmother Spider Woman, and the Tree of Life all exemplify the interrelatedness of Native American cultures. All are extensions of the process of "science" in that they reflect a cultural interpretation based on observation of phenomena and procedures inherent in nature. They represent a very primal and artistically metaphoric way of perceiving - a distinctly Native American way of viewing the world (Cajete, 1999).

Until recently, the arts, hard sciences, and social sciences were presented as totally distinct entities in most American school curricula. Indeed, in many American schools, they still are. 
Such an approach has tended to fragment the human cultural systems being examined, thus perpetuating a distorted perspective of the arts, the sciences and culture in many students' minds. This approach has been particularly unfortunate for Native Americans.

The fact that science is presented entirely from the Western cultural perspective in most American schools can create a genuine psychological conflict for students raised in a different cultural tradition. It is this conflict and resulting alienation that forms the basic impetus for this work.

As is true with all primal cultures, science as a perceiving process was and is completely integrated in all aspects of Native American cultural systems. The method of teaching and learning science today becomes a matter of discovering the products and determining how and why these early thought processes evolved into these paradigms within the context of each tribal culture and environment.

When one interprets and translates the symbolic language, art, dance, music, ritual and other cultural wrappings through which these paradigms have been transmitted, one realizes that they reflect perceptive and sophisticated ideas about the essence of nature and the universe. Research by scientists Capra (1982), Bohm (1983) and others into underlying concepts of many ancient philosophies reveals that many primal sciences have incorporated understandings into their systems that are only now being explored by the most advanced research in quantum physics.

Preliminary attempts are underway to explore the philosophical foundations and ecological practices of primal cultures using the perspectives gained from ecology, the creative process, brain research, linguistics, theoretical physics, anthropology and Jungian and archetypal psychology. This re-examination has great potential in that it presents a method of interpretation of these important paradigms of Native America in the context of the 21st century potentially leading to transformation of science education for more Native American success.

\section{Igniting the Sparkle: An Indigenous Science Education Curriculum Model}

I am an educator of Native American people. What I have been doing and where I have been doing my teaching provides context for understanding what is meant by Indigenous science and the role I play as a Native American educator. I am a Tewa Indian from Santa Clara Pueblo, one of six Tewa speaking villages north of Santa Fe, New Mexico. Each of these Pueblos is autonomous but is related to others through custom and language.

Based on my experience, when a child grows up in a community with other people of their culture who are related or are living the same way, they don't realize their difference. They don't understand the nature of their cultural differences until they become immersed in mainstream society process and culture. My cultural difference didn't impact me until I began interacting with other cultural groups in college. I then realized how different Native American people were and how we viewed life and education in some very distinct ways. To lessen the impact of these differences, I went to a college that was not far from my home, which allowed me to maintain constant contact with my community (Cajete, 1999). 
After graduating from college in 1974 with a degree in biology and sociology, I began to teach high school science at the Institute of American Indian Arts (IAIA) in Santa Fe, New Mexico. The IAIA opened in 1962. The purpose of the IAIA was to evolve a context in which the artistic potentials of young Native American people from all over the United States could be cultivated and expressed. The IAIA was an experiment in cultural education, an experiment using the arts as a primary vehicle, and aimed at helping native young people learn about themselves, their culture and their identity. After its opening in 1962, the IAIA became famous as a model school as UNESCO recognized it as being one of four culturally-based schools of note in the world (see www.iaia.org).

In 1988, Congress enacted new legislation entitled the American Indian Arts and Development Act, which chartered the IAIA as a public/private entity with its own direct congressional funding The Congressional funding of the IAIA remains an experiment because the new legislation is under review. Results of the review will determine if the funding arrangement and sovereign management of the IAIA satisfy both congressional and institutional mandates.

When I started teaching at IAIA, the school had a junior and senior high program as a feeder program for the two-year Associate of Fine Arts degree program in the college. During my first year of teaching, I realized that many of the ways of teaching and approaching science (i.e., textbook science), were not culturally and pedagogically appropriate for my students. Native American students came from all over the United States, and from urban and rural environments. Some were culturally-embedded in terms of their upbringing; others were not. All had a common thread, and that was an interest and a willingness to explore the arts. They also possessed a common alienation from science educational approaches they had experienced in reservation and community schools. Charged with making a program work for these students, I put aside all the textbook methods I had brought with me from the teacher education college and created new curricula based on my own experiences as a Native person. It was pedagogically liberating in that I tried things that would not have been allowed in another school, certainly not in any public school. I explored, piloted, and honed a process that allowed students to learn in ways in which they felt good.

My curriculum evolved over the years from 1974 to 1994. It began with the introduction of ethnobotany in a health science class I was teaching, and it grew into a full culturallybased science program. Its story is a story of creation, of the process of interaction in science, art and culture and the integration of those aspects into the expression of a curriculum - a learning, teaching process that works well for native students who wish to understand and learn about their heritage as it relates to science. The curriculum evolved around the idea that every Indigenous tribe has its own knowledge system and orientation to learning and science, and that the 'epistemological' is metaphorically represented in art forms, stories, ways of community, language, traditional ecological knowledge and positionality in relationship to the natural environment.

I created the curriculum by adapting the Zais Model for Curriculum Research and Design, authored by Robert Zais in 1976. The model uses a rubric composed of four components that sit atop four foundations. The features include: Aims, Goals and Objectives; the Content; Learning 
Activities and Evaluation. These components are directly influenced by the foundations of Epistemology, Society and Culture; The Learner and Theory. The components and foundations were explored to design curriculum for dynamic teaching and learning of basic science concepts in creatively engaging and culturally responsive ways. I similarly approached science learning as the learning of art since both have the creative process of learning in common. In every sense, as Reed (1935) said, "Art is the expression and science is the explanation of the same reality" (p.5). I reviewed the history of Native American ethnoscience and incorporated relevant elements into the presentation of science concepts. Through the research of the curriculum using the Zais model, I was able to show students how science can be viewed as a cross-cultural, multi-contextual knowledge system that has relevance to Native culture and experiences. In the presentation of key concepts, I used native language metaphors, stories, symbols, and art forms to tell the history of "Native Science" while at the same time helping students' development of conceptual understandings of Western Science. What evolved was an integrated view and understanding of culture, science and art as a triad of knowledge and as a kind of complex adaptive systems of inter-relationship.

The integrative research process scaffolded ways for students to engage the natural world and the learning of science concepts personally through art, story and culture. This required looking at the teaching and learning of science in a completely different way and redefining science through the lens of Native thought and cultures. I researched historic and ancient forms of Native American teaching and learning and reintroduced them through the curriculum in contemporary ways. I infused the curriculum with projects that engaged their creativity by learning and creating from life, story and nature. It allowed students to learn art, science, visual thinking and cultural history. It developed in students the ability to create and make the learning of science their own. The curriculum facilitated inner experience and self-reliance through bonding, trust, sharing and caring, thereby bringing students back into an empathetic relationship with plants, animals, place and cosmos through art and science. After a time, the original intent of addressing the alienation of students from science was not only addressed but was transformed into the notions that: science can be learned in multiple ways; that it's about connecting to self and a sense for place; about creating an extended family of learning; about making meaningful connections to life and community; about creating and engaging in authentic learning; about sharing and giving voice and expression to our thoughts; it's about immersion, exploration, appreciation and enhancing personal experience, health and leadership.

I want to emphasize that this curriculum is not an idealized or naïve creation without substance. On the contrary, it is a comprehensively researched and implemented curriculum experienced with positive results by over 2000 students attending IAIA from 1974 to 1994 . This case study illustrates that intervention through the design and implementation of culturallyresponsive science curricula does make a difference in transforming the alienation that many Native American students feel toward science to a feeling and perception that science can have a place in their lives. This transformation of perception is an essential step in creating a foundation for more participation of Native Americans in science and technology-related field. Indeed, one outcome for the students at IAIA who took courses in the curriculum is 
that many later became accomplished in computer-based art production and other uses of science and technology in arts and media. Since that time at IAIA, many other initiatives have incorporated various integrated and cross-disciplinary approaches to science teaching in many school programs and community education projects. Today, these approaches are referred to as Science and Technology Education through Arts and Media (STEAM).

\section{CHART OVERVIEW --THE RESEARCH DESIGN--}

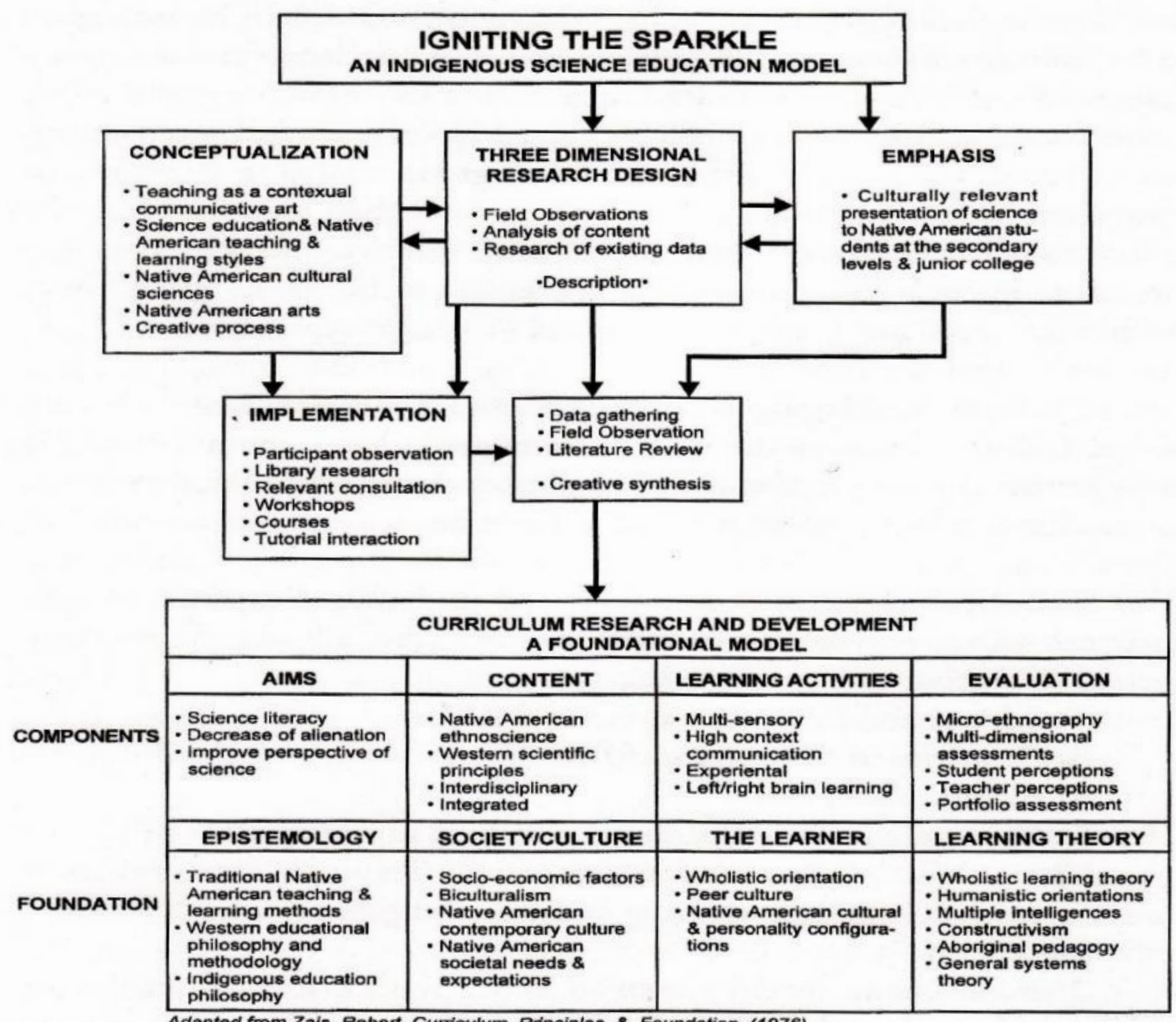

Adapted from Zais, Robert. Curricutum Principles \& Foundation (1976)

Figure 1. Excerpt from Cajete, 1999, p.22. 


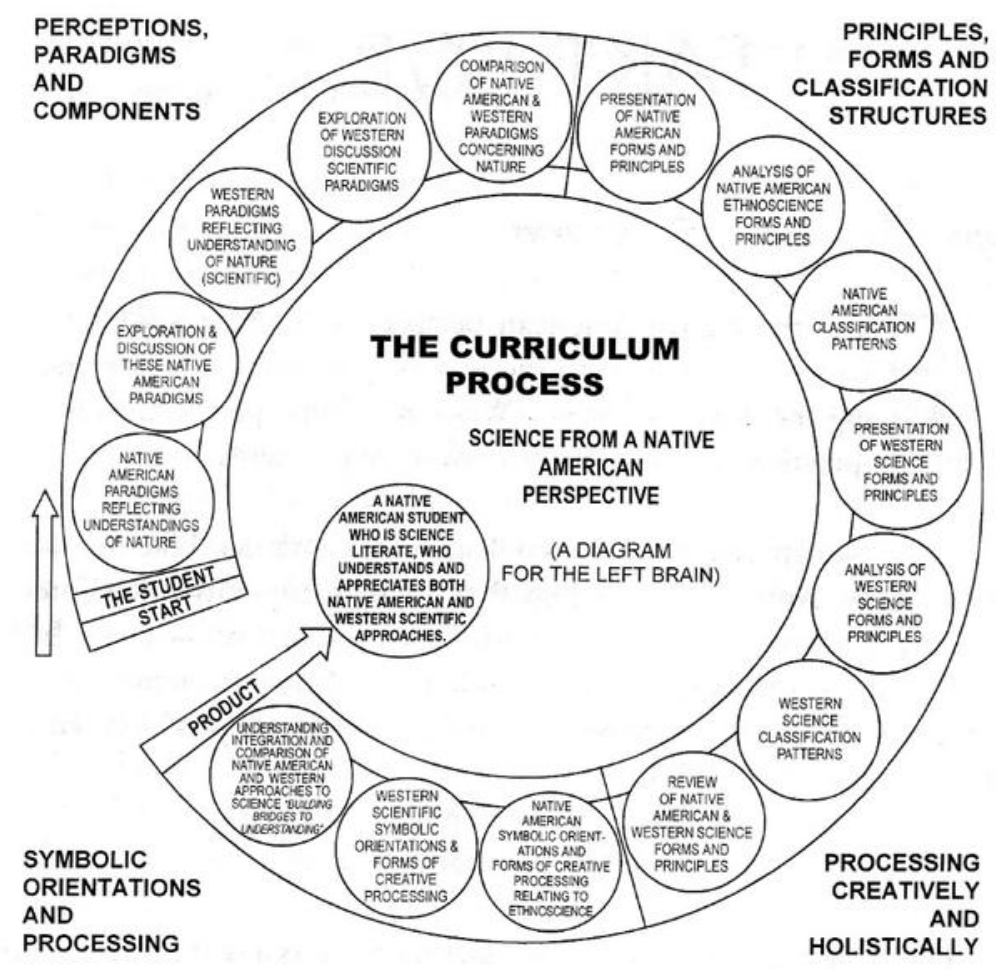

SCIENCE FROM A NATIVE AMERICAN PERSPECTIVE A PROCESS ORIENTED STRATEGY

Figure 2. Science as a cross-cultural discipline. Excerpt from Cajete, 1999, p.115.

\section{The Native American Learner}

Few studies have seriously explored the unique and culturally conditioned learning characteristics of Native Americans. Until interest in field sensitive vs. field independent orientations (Ovando \& Collier, 1985) by some minority group learners emerged, few researchers had focused on the notion that the most effective way to educate was to develop teaching and learning strategies around distinct learning styles. Based on the concept of cultural deprivation, the prevailing notion had been to change the learning style through educational reconditioning so that students would conform to the mainstream educational system (Cajete, 1999; Burke, 2007). From the earliest missionary attempts through the boarding school era to the present stage of public school education, Native American education has been dominated by attempts at reconditioning Native American learning styles.

In my work, I resolved this focus on reconditioning by developing my lessons using a creative process methodology of insight first (Why), preparation/immersion (What); experimentation (How), and presentation (What If). This four-fold process parallels Native thought and insight inherent in the medicine wheel orientations of the four directions and the application of the 
scientific method's application of observation, analogy, experimentation and presentation of results. I taught each of my units using an integration of all three parallel approaches to teaching and learning (Cajete, 1999).

Fortunately, with the introduction of self-determination and the concurrent trend of cultural revitalization in Native education, this inherent focus of reconditioning Native students through Western schooling is beginning to change. To continue such a movement toward a more culturally relevant and learner sensitive education, some critical factors must be considered. Significant learning tends to be directly related to the degree of personal relevance the student perceives in the presented educational material. The basis for such a premise stems from the idea that motivation toward any pursuit is energized by one's own constellation of personal and socio-cultural values. In the Native American social psyche, this constellation of values has very ancient and well-developed roots. It is because of this embeddedness that Native American social personalities remain so durable and relatively visible through layers of acculturation. Understanding and utilization this cultural constellation of values is a key to motivating learning in Native American education.

Since the turn of the century, Native Americans have experienced various levels of acculturation. Acculturation led to new configurations of language and culture characteristic of the changes a particular Native American group underwent. For instance, many Native American students can be classified as "English dominant," which has ramifications for teaching science. For while many are English dominant, they have been exposed, through home and community, to various levels of thought concerning how their particular tribal groups have traditionally viewed the natural world. There is often a real identification with both the cultural and linguistic revitalization of their specific cultural group. This sense of identification with tribal roots can provide a prime source of motivation to learn about science related to an individual's heritage.

In addition to students rediscovering their tribal identities and ancestral knowledge systems, there are more bilingual and bicultural students. These students generally want to continue to learn and live within the context of both knowledge systems. Instruction in transsystemic science for these students constitutes a real enrichment of their attitudes toward science and reaffirms cultural ties and identifications with their tribal groups. Science instruction from two cultural views for these students provides a means of bridging the significant differences in mindset concerning natural phenomena. This approach to science instruction is by its nature a two way approach in that while Indigenous students are learning Western science building from and on their ancestral systems of knowledge, non-Indigenous students are learning and considering other cultural ways of knowing nature that enhances the knowledge gained from Western science.

Knowledge of Native American core cultural values and how such values differ from the values implied in American education is essential in bicultural education (Brandt \& Kosko, 2009). The transition of values has a direct effect on their attitudes toward education. Core cultural values of Native Americans and their influences on attitudes and behaviours are relatively submerged since such values tend to operate at the subconscious level. 
These values, however submerged, invariably affect the outcome of their educational pursuits. If the student can be made aware of Indigenous knowledges of their people, learning will follow. Showing the student how what is being presented in a particular area such as science is relevant to or enhances the understanding of those cultural values will help him/ her to learn. The student's values play a key role as psychological "energizers" for the positive evolution of self-image.

Since the 1940s, the accelerated rate of development has increased the inconsistences in worldview and cognitive fabric of Native American life, resulting in much intrapersonal tension. This conflict has given rise to a variety of emotional and social problems whose ramifications are poorly understood. But a subtle, well-integrated and consistent cognitive map and world view are conducive to healthy concepts of self and positive social adjustment. The opposite is usually apparent when there are acute or chronic inconsistencies and conflicts between the internal constellation of values and those of the external social environment.

Cultural content will facilitate educational goals and the development of students both intellectually and socially. Bringing core cultural values from the subconscious to the conscious sets the stage for the creative synthesis and interpretation of those values in a new and psychologically rewarding context.

\section{Border Crossings}

There is an acknowledgement that distinct cultural knowledge systems exist and have always existed through history, which have developed and applied their forms of "science" to their societal needs. Indeed, the notion that Western science is a rational approach to knowing in Eurocentric disciplinary knowledge system presents an inherent bias for all students learning science in Western schools. This realization has influenced mainstream science educators, opening the way for a contemporary Indigenous expression of education through cross-cultural science curriculum tailored to students' needs.

According to Aikenhead (1997), learning Western science requires Native students to cross cultural boundaries, from the familiar contexts of peers, family and tribe, to school, school science and the actual world of science. The notion of border crossings is an anthropological metaphor that implies that students do not leave their home culture behind when they enter this cultural landscape called "School Science." In a sense, they are on a mission to learn about a new territory to gain knowledge and understanding that they may use back home toward their self determined and practical ends. These practical ends include preparing for a career, economic development, environmental responsibility and cultural survival at the community level (Aikenhead, 1997). In interactions between Indigenous cultures and the subculture of Western science, profound conflicts arise. Their orientations differ in terms of survival vs. power over nature and other people; coexistence with the mystery of nature vs. attempting to explain the mystery of nature away; the search for an intimate relationship with nature vs. decontextualized objectivity; and accommodation, intuitive and spiritual vs. reductionist, manipulative and analytical. 
Indigenous knowledge of nature tends to be thematic, survival-oriented, holistic, empirical, rational, contextualized, specific, communal, ideological, spiritual, inclusive, cooperative, coexistent, personal, and peaceful (Aikenhead, 1997, p.7). This essential orientation difference challenges Native American students as they attempt to cross the borders into the subculture of western science as represented in schools. If the teaching and learning of science support the student's cultural orientation, "enculturation" results. If the teaching and learning of science is at odds with the student's cultural orientation, the result is "assimilation," forcing students to abandon or marginalize their way of knowing to reconstruct a new (generally dysfunctional) way of knowing. Unfortunately, the latter is more often the case.

The essential question is: How can students from Indigenous cultures learn any subjects like science without being assimilated harmfully by the underlying value structure in the unfamiliar knowledge system used? I posit that First Nations students should develop the facility to cross from everyday sub-cultures of peers, family, community, and tribe into the sub-cultures of school science, science and technology (Pomeroy, 1994). Students and teachers should become "cultural border-crossers" (Pomeroy, 1994, p. 17). Yet, "crossing over from one domain of meaning to another is exceeding hard" (Hennessey, 1993, in Aikenhead, 1997, p. 9). Students generally get very little help doing this kind of border crossing. Few teachers are inclined to assist students, and if they are, they have few resources for being trained in this kind of cross-cultural, trans-systemic negotiation.

Four worlds for student transitions have been identified. These include: a congruent world that supports smooth transitions, a different world that requires transitions to be managed, diverse worlds that lead to hazardous transitions, and highly discordant worlds which cause students to resist transitions and in which they become virtually impossible (Phelan, Davidson, \& Cao, 1991).

Costa (1995) divided minority students in science classrooms into a typology:

1. "Potential Scientists" cross borders into school science so smoothly and naturally that the borders appear invisible;

2. "Other Smart Kids" manage their border crossing so well that few express science as being a foreign subculture;

3. "I Don't Know Students" confront hazardous border crossings but learn to cope and survive;

4. "Outsiders" tend to be alienated from school so the border crossing in school science is virtually impossible; and

5. "Inside Outsiders" find the border crossing almost impossible because of overt discrimination within the school.

Helping students develop the skills for "raiding Western science for practical ends and achieving goals defined by first nations science education" (Aikenhead, 1997, p. 11) must be a key aim in developing a science curriculum for Native students. Determining what kinds of skills and knowledge are appropriate for "First Nations students" to learn concerning economic 
development, environmental responsibility, and cultural survival is the next step of developing such a comprehensive process. Sound integrated education that helps students be flexible and adaptable and enhances their ability to train on the job is the most strategic form of science education.

Jenkins (1992) argues that using science in everyday situations requires changing knowledge into new forms that can be applied to emerging issues. Restructuring scientific knowledge into new shapes for Native contexts requires knowledge of both a different cultural orientation and a different approach to teaching and learning science. Essentially, Native knowledge comes already contextualized and ready for use; Western scientific knowledge does not. As this is how Western science is taught in school, it is no wonder that many students cope by developing a view of science as existing apart from their real lives. An approach that weaves scientific, technological and Indigenous knowledge into real-life situations and issues has the best chance of being effective. Participatory research by teachers and students is one way of accomplishing this.

MacIvor (1995) proposes that integrating selected science and technology content in an Indigenous worldview requires coordination with relevant economic, social and resource needs. One might apply a cross-cultural Science-Technology-Society (STS) model used by science educators in third world countries. STS is a dedicated student-oriented, critical and environmentally responsible approach to science, and it decontextualizes Western science in the social and technological settings relevant to students (Aikenhead, 1994).

Applying an anthropological approach from an Indigenous perspective to the teaching and learning of Western science is another possibility since this promotes "autonomous acculturation, (or) intercultural borrowing or adaptation of attractive content or aspects" (Aikenhead, 1994, p. 23). This would be a more constructive and culturally affirming alternative for Native students than assimilating, or enculturating themselves to Western science. Students may act as anthropologists learning about another culture. Like cultural anthropologists, they would not need to accept the cultural ways of their "subjects" to understand or engage in some of those ways (Aikenhead, 1994).

Combining the STS approach with that of "the student as anthropologist" in an Indigenous perspective and community reality can form an ideal foundation for Indigenous students' learning of science. The teacher's role is to learn to act as a cultural broker who assists students in handling cultural negotiation and conflict between views.Students act as "cultural tourists" in a constructive way, and teachers take on the role of "tour guides" and "travel agents" as they help students cross the cultural knowledge borders between science and their own experience.

The development of such a curricular approach can further be facilitated by studying the students' community reality and using that as a foundation for relevant and meaningful themes, then comparing that foundation with Western science's subculture. 


\section{Final Thoughts}

Western science education is most oft at odds with the diversity of socio-cultural environments from which many Native American students come. For example: Learning to hunt in a traditional Native American society context is a programmed sequence of observations and experiences tied to a process which might include:

1. Learning the habits of the animal hunted (mythology, listening and observation);

2. Learning to track, read appropriate signs and stalk the animal (observation, intuition and reasoning);

3. Learning the proper respect and ritual to be extended to the animal hunted (learning a mindset);

4. Learning to properly care for the carcass of the animal once it has been taken (an ecological ethic, technology); and

5. Learning to fully utilize the various parts of the animal taken (technology).

These processes require teaching techniques ranging from formal instruction to experiential learning. These teaching/learning situations are directly related to a particular contextual framework necessary for conveying these forms of knowledge. Learning is directly tied to the task. It involves teaching to accomplish a specific goal. One observes and learns from that which one seeks to do. The teachers and situations are many.

Native American cultural education revolves around the problem of learning how to do something. By contrast, modern Western education revolves around frames of reference that prepare students for future needs and tasks deemed important in a modern industrial and technological society. As a result, within most typical American educational situations, what is learned is laid out in a distinct linear pattern. All that is to be known is hierarchically mapped beginning with objectives to be reached in each grade level and moving to more specific units and individual lesson plans, each of which has objectives and associated learning activities. This highly structured and programmed approach is designed for more straightforward teaching of large numbers of students and for consistency in what is learned. Yet if one views this approach in terms of addressing individual student learning styles, many problems become apparent.

Much of modern education imposes a preconceived psychological pattern of the "right and wrong ways to do things." This pattern imposes Eurocentric will on all those who participate in American public education. Indeed, it is a form of bias ranging from structural/systemic racism to cognitive imperialism and epistemic violence. In the process, many students are denied the use of their innate repertory of intelligences and cultural styles of learning drawn from their Indigenous knowledge system. Ability to learn by simply doing, experiencing and making connections will be significantly diminished through such a homogenization of the educational process.

Being positioned how I am as an educator for most of my career has meant I have biases which may have come out in this essay, however, I use my position to invite the sharing of experiences and expertise, and to support joint actions such as combining Indigenous and 
Western approaches to science and technology in effective and sensitive ways. This essay asks other educators to do the same. I look to the new generation of educators to continue the advancement of a trans-systemic education culture, and to monitor, using both Indigenous and Western ways, our progress in the coming years.

\section{Notes}

1. Portions of this chapter have been adapted from a previously published work:

Cajete, G. A. (1999). Ignite the sparkle: An Indigenous science education curriculum model. Kivaki Press.

2. The terms Indigenous, Tribal, Tribe, and First Nations are capitalized to emphasize and convey an active and evolving identity. The term Indigenous is used as the more extensive inclusive group term, while Tribal refers to specific contexts. Both terms are capitalized as an honourific designation. Native American, Native, or American Indian are used when referring specifically to Tribes that reside in the United States. These terms are not used in Canada, where the preferred terms are Aboriginal, First Nations or Indigenous Peoples.

\section{About the Author}

Gregory Cajete is a Native American educator whose work is dedicated to honouring indigenous knowledge foundations in education. He is a Tewa Indian from Santa Clara Pueblo, New Mexico and has lectured at colleges and universities in the U.S., Canada, Mexico, New Zealand, Italy, Japan, Russia, Taiwan, Ecuador, Peru, Bolivia, England, France and Germany. He worked at the Institute of American Indian Arts in Santa Fe, New Mexico, for 21 years. While at the Institute, he served as Dean of the Center for Research and Cultural Exchange, Chair of Native American Studies and Professor of Ethnoscience. He is the former Director of Native American Studies and Emeritus Professor in the Division of Language, Literacy and Sociocultural Studies in the College of Education at the University of New Mexico. Dr. Cajete has authored or co-authored ten books, including Look to the Mountain: An Ecology of Indigenous Education (Kivaki Press, 1994), Ignite the Sparkle: An Indigenous Science Education Curriculum Model (Kivaki Press, 1999), and Indigenous Community: Rekindling Teachings of the Seventh Fire (Living Justice Press, 2015). Email: gcajete@unm.edu 


\section{References}

Aikenhead, G. (1997). Toward a First Nations cross-cultural science and technology curriculum. Science Education, 81, 217-238.

Aikenhead, G., \& Mitchell, H. (2011). Bridging cultures: Indigenous and scientific ways of knowing. Pearson Canada.

Bohm, D. (1983). Wholeness and the implicate order. Ark Paperbacks.

Brandt, C. B., \& Kosko, K. (2009). The power of the earth is a circle: Indigenous science education in North America. In The World of Science Education (pp. 389-407). Brill Sense.

Burk, N. M. (2007). Conceptualizing American Indian/Alaska Native college students' classroom experiences: Negotiating cultural identity between faculty and students. Journal of American Indian Education, 1-18.

Cajete, G. (1994). Look to the mountain: An ecology of Indigenous education. Kivaki Press.

Cajete, G (1999). Ignite the sparkle: An Indigenous science education curriculum model. Kivaki Press.

Cajete, G. A. (1999). The Native American learner and bicultural science education. in: "Next Steps: Research and Practice To Advance Indian Education"; see RC 021798 URL: https://files.eric. ed.gov/fulltext/ED427908.pdf

Cajete, G. (2000). Native science: Natural laws of interdependence. Clear Light Publishers.

Capra, F. (1982). Turning point. Simon and Shuster.

Costa, V. B. (1995). When science is 'another world': Relationships between worlds of family, friends, school, and science. Science Education, 79, 313-333.

Dunn, R. (1983). Learning styles at both ends of the spectrum. Exceptional Children, 49(6). https://doi.org/10.1177/001440298304900602

Greene, R. (1981). Culturallybased science: The potential for traditional people, science and folklore. London: Proceedings of the Centennial Observation of the Folklore Society.

Hall, E. T. (1976). Beyond culture. Anchor Books/Doubleday.

James, K. (Ed.) (2001). Science and Native American communities: Legacies of pain, visions of promise. University of Nebraska Press.

Hennessey, S. (1993). Situated cognition and cognitive apprenticeship: Implications for classroom learning. Studies in Science Education, 22(1), 1-41. https://doi.org/10.1080/03057269308560019

Jenkins, E. (1992). School science education: Towards a reconstruction. Journal of Curriculum Studies, 24, 229-246.

Leshner, A. (2011). We need to reward those who nurture a dive: Teaching in multiversity of ideas in science. Retrieved from

http://chronicle.com/article/We-Need-to-Reward--Those-Who/126591/

Longino, H. E. (1990). Science as social knowledge: Values and objectivity in scientific inquiry. Princeton University Press.

MacIvor, M. (1995). Redefining science education for Aboriginal students. In M. Battiste \& J.

Barman (Eds.), First Nations education in Canada: The circle unfolds. (pp.73-98). UBC Press.

Mansfield, R. S. (1978). The psychology of creativity and discovery. Nelson-Hall.

Maruyama, M., \& Harkins, M. (1978). Cultures of the future. Mouton.

Medin, D., \& Bang, M. (2014). Who's asking? Native science, western science, and science education. MIT Press. 
Milne, B.T. (2017). Dynamics to justify strategies to close the baccalaureate attainment gap in tribal communities of New Mexico. (Unpublished manuscript). April 27, 2017.

Ovando, C. J., \& Collier, V. (1985). Bilingual and ESL classrooms: Teaching in multicultural contexts. McGraw-Hill.

Phelan, P., Davidson, A., \& Cao, H. (1991). Students' multiple worlds: Negotiating the boundaries of family, peers, and school culture. Anthropology and Education Quarterly, 22, 224-250.

Pomeroy, D. (1994). Science education and cultural diversity: Mapping the field. Studies in Science Education, 24, 49-73.

Read, H. (1945). Education through art. Pantheon Books.

Sanders, D. A. (1986). Teaching creativity through metaphor: An integrated brain approach. Longman.

Van Peursen, C. A. (1981). Creativity as a learning process in the concept of creativity in science and art. Martinus Nijhoff.

Whorf, B. L. (1956). Language, thought and reality. MIT Press.

Zais, R. (1976). Curriculum principles and foundations. Harper \& Row. 